\title{
ACCESS TO STANDARD ESSENTIAL PATENTS AND ANTITRUST ENFORCEMENT: THE CASE FOR LICENSING COMPONENT MANUFACTURERS
}

\section{INTRODUCTION}

Access to technical standards is very important in numerous industry sectors. Since standards are often patent protected, such access requires the licensing of patents that are essential to the practice of these standards. Developing such standards often requires substantial investment in R\&D, for which the patent holders want to be rewarded. But patent holders also try to take advantage of the fact that they possess an asset that is indispensable in order to be able to compete on various markets. This leads to patent wars between the right holders and manufacturers who implement technologies based on patent protected inventions in their products or those who distribute such products. Unsurprisingly, disputes concerning standard essential patents attracted a significant degree of attention from scholars who concentrated on the availability of injunctive relief and reasonable royalties.

Recently, the issue that is particularly debated in multiple jurisdictions is the practice of standard essential patents (SEPs) holders refusing to license the manufacturers of components where such patented inventions are implemented (such as chips allowing communication with mobile networks), and instead licensing the manufacturers of final products (such as mobile phones or smart cars). The major question is whether such a practice of patentees should lead to liability under competition laws. The interface between IP and competition law has always been a subject of intensive scholarly debate. The issue of licensing at the component level offers a chance to look at that interface once again.

This paper aims to analyse the role (if any) that competition law could play in ensuring access to standard essential patent licenses for component manufacturers. In order to achieve this, paper begins with a short introduction of the problems related to standardization and access to SEPs. It also briefly presents the disputes concerning the licensing of SEPs and the potential role for competition law. Then the author describes the market power that results when a patent, upon adoption of a standard, becomes standard essential, and the dangers of hold-up by the patentees and hold-out on the side of the implementers. Having introduced the most fundamental concepts, 
the author moves to analysing refusals to license as a form of exclusionary conduct capable of harming competition. Section 6 of the paper exclusively assesses refusals to license component manufacturers from the perspective of competition law. Finally, the author presents conclusions that can be drawn from the research conducted.

\section{TECHNOLOGICAL STANDARDS, STANDARD-SETTING AND STANDARD ESSENTIAL PATENTS}

Technical standards play an important role in the modern economy. They are present in numerous industries. However, it is likely that standardization has been nowhere more important than in the Information and Communication Technology (ICT) market. Standards such as 4G, 3G, WiFi, Bluetooth or USB are commonly used around the world. The benefits that come with technical standardization can hardly be overestimated. Standards enable the interoperability of devices, often manufactured by market competitors. ${ }^{1}$ They also encourage further investment in the development of technologies that build upon access to standards. ${ }^{2}$ Standardization in the telecommunications sector not only allowed mobile telecommunication networks to be built, but also, by allowing for the transmission of large sets of data, enabled the creation of numerous new platforms and services, most notably in the transportation, media and entertainment sectors. ${ }^{3}$ The ubiquitous application of technical standards will be even more visible with the rise of $5 \mathrm{G}$ networks and the Internet of Things (IoT). ${ }^{4}$

Standards are developed through the cooperation of numerous market participants which takes place within standard development organizations, (SDOs). ${ }^{5}$ Within such organizations participants agree upon the technical specifications of a given standard. ${ }^{6}$ Modern standards are frequently quite complicated and various parts of those standards are protected by the patents held by numerous patent holders. ${ }^{7}$ The proprietary nature of modern technical standards may be problematic. Patents that concern technical standards are after all exclusive rights that may be used by rights holders to extract excessive royalties and other unfair terms from standard implementers or - in more extreme cases - even to block access to markets where a given standard is implemented. SDOs, which are interested in the success of standardization and in the wide adoption of their standards, are well aware of these dangers. For that purpose, since the first half of the twentieth century SDOs have re-

\footnotetext{
${ }^{1}$ Contreras (2018): 1; Regibeau, de Cornick, Zenger (2016): 5.

2 Pohlmann, Blind (2016): 6.

3 Teece (2019): 15.

${ }^{4}$ Gupta (2019): 29-30.

5 Biddle (2018): 17-28.

${ }^{6}$ Gupta (2018): 33-34.

7 Pohlmann, Blind (2016): 10-35.
} 
quired the holders of patents essential to the practice of a given standard to disclose their patents or patent applications that may concern that standard and also to commit themselves to licensing their patents to all potential licensees on fair, reasonable and non-discriminatory (FRAND) terms. ${ }^{8}$

Access to standard technologies is a perquisite for presence on those markets where standards are implemented. In the world of IoT, consumers expect their mobiles as well as numerous other products, ranging from autonomous cars to home devices, to comply with such standards. ${ }^{9}$ In the case of proprietary standards, which account for the majority of widely used technical standards, access to such technologies requires obtaining rights to practice inventions protected by SEPs. In practice this means that anyone who intends to implement a given technological standard must conclude licensing agreements with SEP holders. Given the complexity of standards today, this might require concluding quite a significant number of SEP licensing agreements. SEP holders are thus the gatekeepers to markets where standards are implemented.

\section{DISPUTES CONCERNING ACCESS TO SEPs: THE ROLE OF COMPETITION LAW}

Unsurprisingly, there has been quite a significant amount of litigation concerning the terms of SEP licenses around the world. Indeed, the implementers and technology developers seem to have potentially conflicting interests. Standard implementers are interested primarily in paying as little as possible for the rights to use SEP-protected technologies. ${ }^{10}$ They often claim that SEP holders take advantage of the fact that implementers have usually already incurred significant investment costs and that they may no longer switch to third party technologies. All this leads to the SEP holders being in a position to demand unfair and unreasonable licensing terms, including excessive royalty rates. ${ }^{11}$ Technology developers, on the other hand, not unexpectedly claim that in order to maintain conditions favourable to innovation, they must be in a position to extract royalties that could cover their $R \& D$ costs and thus maintain incentives for further innovation. ${ }^{12}$

So far both litigation and legal literature has concentrated on the ability of the SEP holders to obtain injunctive relief in patent infringement disputes with standards implementers. Courts in various jurisdictions have quite consistently limited the availability of injunctions against SEP implementers when SEP holders made a commitment to an SDO to license on FRAND terms and the implementers were willing to negotiate an SEP licensing agreement

\footnotetext{
8 Gupta (2018): 35-36.

9 Pohlmann, Blind (2018): 6.

10 Barnett (2019): 55.

11 Barnett (2019): 54.

12 Teece (2019): 16.
} 
in good faith. ${ }^{13}$ This effectively deprived the SEP holders of a powerful tool of threatening the implementers willing to conclude a license with an injunction in order to obtain more favourable licensing terms, particularly higher royalties. Additionally, courts and scholars have also tried to establish what the fair, reasonable and non-discriminatory licensing terms are. Thus, the balance between the interests of implementers and technology developers has been in principle achieved through a flexible rather than rigid approach towards injunctions, in particular the approach that includes (some sort of) proportionality as a governing principle for patent remedies, as well as through the interpretation of FRAND commitments made by SEP holders in the context of standard setting process.

Recent developments in numerous jurisdictions have shown growing reliance on competition law ${ }^{14}$ as a means of policing SEP holders' abusive conduct. This is particularly the case with respect to the patentees' practice of refusing to license SEPs to manufacturers that produce components (such as chips responsible for wireless communications) and instead licensing manufacturers of final products (such as mobile phones or cars). Such refusals are seen as exclusionary conduct capable of restricting or eliminating the competition. Refusals to conclude licensing agreements for the use of SEPs with component (chip) manufacturers resulted in competition proceedings by the competition authorities in South Korea, ${ }^{15}$ Taiwan, ${ }^{16} \mathrm{China}^{17}$ and more recently also in the United States, in the now famous FTC $v$. Qualcomm case. ${ }^{18}$

Competition law is certainly a powerful tool, the application of which is capable of influencing the conduct of both standards implementers and those who are holders of standard essential patents. Competition authorities usually have the power to demand that market participants cease certain conduct (they may either seek injunctions against certain practices by SEP holders in the courts or issue such injunctions themselves) as well as to impose fines when they find the conduct to have violated competition rules. Those who

13 See, among others: Siebrasse et al. (2019): 134; Contreras et al. (2019): 171-190; Sikorski (2018): 242-245.

14 In the article the terms 'antitrust law' and 'competition law' are used interchangeably when discussion turns to EU law, the latter term is preferred, whereas when the discussion concentrates on US law, the term 'antitrust law' is used.

${ }^{15}$ Korea Fair Trade Commission Decision from 21 December 2016 imposing remedial orders against Qualcomm Inc. and two of its affiliates. The decision was upheld on 4 December 2019 by the Seoul High Court.

16 Taiwan Fair Trade Commission Decision from 11 October 2017 imposing, among others, a monetary fine on Qualcomm Inc. The case was later settled between the TFTC and Qualcomm Inc.

17 National Development and Reform Commission decision from 10 February 2015 imposing administrative penalty against Qualcomm Inc.

18 US District Court Northern District of California, Federal Trade Commission v. Qualcomm Inc., Case No. 17-CV-00220-LHK. The decision of the District Court was appealed to the Court of Appeals for the 9th Circuit (9th Cir.). The paper was submitted prior to the Court of Appeals for the 9th Circuit giving its judgement in Federal Trade Commission v. Qualcomm Inc., Case No. 19-16122, and does not include the discussion of that decision. 
have suffered as a result of anticompetitive practices may demand damages and, in some jurisdictions such as the US, even treble damages.

This rather severe nature of sanctions for infringements of competition law requires a cautious application of such rules to the exercise of intellectual property rights, including patents. In particular, the application of competition law should not undermine the incentives for innovation that lie at the foundation of patent law. Patent law encourages innovation by granting exclusive rights for a limited period. By doing so, patent law also encourages innovation with regard to existing patents. The exercise of patent rights however is not immune from scrutiny under competition law, which forms a framework within which the exercise of all rights, including patents, takes place. In fact, there seems to be quite a broad consensus today that the two bodies of law have similar goals. Both encourage dynamic competition, namely competition through innovation. Patent law, in particular, provides for exclusive rights and encourages innovation by the replacement of older products with new ones. From a competition law perspective, dynamic competition results in new products capable of better satisfying the needs of consumers.

\section{SEPS AND MARKET POWER: THE HOLD-UP AND HOLD-OUT DILEMMAS}

It should not be surprising that exercise of standard essential patents comes under the scrutiny of competition law. Patents as such do not grant market power just by virtue of being exclusive rights. SEPs are different, however, once a standard is adopted, the ability to compete on the market depends upon access to such a standard, and if that standard is protected by patent rights, such access requires a license. Clearly, the position of the patentee changes with the adoption of a standard that includes a patented invention. Prior to standard setting there usually are competing alternatives to the patented invention. ${ }^{19}$ The market power of the patentee is constrained by other technologies. But when the standard is adopted, and when there are no viable alternatives to that standard, the negotiating position of the patentee vis a vis third party implementer radically changes. ${ }^{20}$

It is precisely because SEP holders obtain market power as a result of standardization that a hold-up problem may occur. Patent hold-up refers to a situation where the patentee may delay the conclusion of a licensing agreement until his demand for royalties which exceed the value of the licensed invention is met. ${ }^{21}$ Lacking alternatives, implementers are locked-in to a given technology. Often, they also incur substantial costs resulting from the implementation of those technologies. These costs would be lost if the implementer

\footnotetext{
19 Hovenkamp (2019): 6.

${ }^{20}$ Hovenkamp (2019): 6-7.

21 Lemley, Shapiro (2007): 1993.
} 
had to abandon practicing a standard. ${ }^{22}$ In such circumstances, facing exit from the market and substantial sunk costs, implementers are usually willing to accept even excessively high royalties. Such excessive royalties are later reflected in product prices. Consequently, consumers end up paying more for their products. This in turn may reduce the overall consumer welfare.

The existence of hold-up has been subject to severe criticism in legal and economic literature. Critics usually claim that no evidence of the existence of hold-up has been presented. ${ }^{23}$ In fact, claim the critics, the overall prices for standard compliant products have gone down. Neither has there been a significant royalty stacking problem, because the overall royalty burden has been maintained within reasonable limits of the overall price for the standard compliant products. Critics point to empirical studies which state that the overall royalty burden is around low to mid-single digit numbers. ${ }^{24}$ Barnett also suggest that in fact SEP holders are generally repeat players, thinking about their profits in the long term perspective which includes taking into account the fact that by charging excessive royalties they might be punished by implementers not willing to implement their technologies in the future. This long term perspective disciplines the royalty claims made by patentees. ${ }^{25}$ Delrahim - also critical of hold-up - rejects the idea that higher prices reveal the existence of a competition law problem and is rather willing to treat such prices as an indicator of a product's success, resulting from its superiority over its alternatives. ${ }^{26}$

However, the belief that hold-up does not exist is contradicted by numerous disputes over royalty rates. Such disputes point to an existing gap between the initial demands by SEP holders and the amounts of royalties finally awarded by the courts, not only in the US but also in the EU and Asia. ${ }^{27}$ It is not difficult to imagine that without a flexible approach towards injunctive relief SEP holders would be in a position to extract significantly higher royalty rates, as the implementers would either accept them or otherwise would be forced to exit the market.

Hold-up sceptics refer to the phenomenon of hold-out. Hold-out strategies will vary, depending on the type of implementer. Some implementers hope that they will not be caught. In the case of larger enterprises, a hold-out describes a strategy of an implementer to withhold payment of royalties in order to obtain lower rates. ${ }^{28}$ Recently, Delrahim pointed to collective hold-out,

${ }^{22}$ Lemley, Shapiro (2007): 1993.

${ }^{23}$ Barnett (2019): 55.

${ }^{24}$ Barnett (2019): 54.

${ }^{25}$ Barnett (2019): 55.

${ }^{26}$ Delrahim (2018): 8.

${ }^{27}$ The letter by 77 former government enforcement officials and professors of law, economics, and business to Assistant Attorney General Makan Delrahim, 17 May 2018. The text of the letter is available at: <https://law.rutgers.edu/f/mc-05-18-2018.pdf $>$. The authors referred to a number of cases where the courts have awarded royalties which constituted only a fraction of what the patentees initially demanded.

${ }^{28}$ Barnett (2019): 55; Delrahim (2017): 5. 
which is a hold-out strategy where the implementers jointly exert power (buyers' power) to effectively lower the royalties due. ${ }^{29}$

Successfully addressing concerns resulting from both hold-up and holdout depends largely on how the remedies are structured, and particularly how injunctive relief in patent law is structured. When administering patent remedies allows for flexibility, it is very unlikely that SEP holders could threaten SEP implementers with injunctive relief to obtain higher royalties. As long as there is willingness to conclude a license on the part of the implementer, SEP holders should be held to their FRAND promises and injunctive relief should be denied. Similarly, the potential for hold-out is small when an implementer is required to act expeditiously and without unnecessary delay when negotiating a license. ${ }^{30}$

\section{REFUSALS TO LICENSE SEPS AS EXCLUSIONARY CONDUCT}

Since having access to a technical standard is necessary for market participants to compete on product markets where standards are implemented, the refusal to license a SEP leads to a situation where an implementer infringes a SEP holder's patent. In this case, manufacturing and the sale of a product incorporating a patented invention could lead to liability for patent infringement, including injunctive relief, damages and, in jurisdictions where that is possible, also disgorgement of profits. Thus, refusal to license may result in market foreclosure, it may result in less competition on downstream product markets where standards are implemented, both in terms of price competition, but also and more importantly, less competition with respect to innovation that builds on access to standard technologies.

Refusal to license a SEP may be unconditional. ${ }^{31}$ In this case, a patentee simply refuses to license. A SEP holder may be especially interested in doing this when they are present on the downstream product market where the technology is implemented. Here, no licensing conditions are even specified by the SEP holder. In practice, SEP holders rarely employ such a blatantly exclusionary conduct. More frequently, SEP holders specify licensing conditions in a licensing offer. However, these conditions are either so restrictive, excessive, or sometimes clearly infringing competition laws, ${ }^{32}$ that they cannot be regarded as meeting the requirements resulting from FRAND commitments made by SEP holders in the standard-setting process and thus need not be accepted by implementers.

In many jurisdictions, courts have been able to deal with patent disputes concerning SEP licensing by resorting to contract laws and patent remedies

\footnotetext{
${ }^{29}$ Delrahim (2017): 5 .

30 Sikorski (2018): 47-49.

31 Hovenkamp (2019): 11.

32 Hovenkamp (2019): 15.
} 
in order to deny injunctive relief against implementers willing to conclude a licensing agreement on FRAND terms. In such cases, courts ordered payment of royalties instead of granting injunctions. ${ }^{33}$ In Germany, where patent law did not envisage flexibility in the application of injunctive relief in patent disputes, ${ }^{34}$ courts have resorted to competition law as a defence against a patentee's demands for injunctive relief. ${ }^{35}$ Effectively, at least with respect to SEPs, German courts now offer protection against patentees who wish to enforce their patents against standard implementers willing to conclude a license on FRAND terms.

In Huawei v. ZTE the dispute concerned one of the Huawei's patents which was necessary to use LTE technology. ${ }^{36}$ Because the parties to the dispute could not agree on the terms of the FRAND license, Huawei finally sued ZTE in the Dusseldorf court in order to obtain an injunction. ZTE claimed that by demanding an injunction Huawei had abused the dominant position it held on the technology market. The CJEU recognized the right of the patentee to injunctive relief, but stated that in the case of standard essential patents when the implementer is willing to conclude a licensing agreement, the patentee should not be able to obtain an injunction.

The CJEU provided a framework to assess whether the licensee is willing to conclude a licensing agreement and whether the licensor is willing to license on FRAND terms. ${ }^{37}$ The framework provides for a balanced procedure for negotiations that aims to protect both the interests of the licensors and the licensees. This is achieved by requiring the patentee to specify which SEPs are implemented by the implementer, allowing the implementer to assess whether indeed a given SEP is valid and implemented. Thus, implementers are protected against vaguely formulated notices often used by patent assertion entities. The SEP holder is also required, at the request of the implementer, to present a licensing offer which should include royalty rates and also explain how these rates were calculated. The licensing offer should also be non-discriminatory. The CJEU also requires that the parties negotiate in good faith and act promptly. If the dispute as to the contractual terms cannot be resolved amicably, the parties should agree to an independent third-party determination.

The procedure for negotiations of a SEP license protects both against hold-up and hold-out. The practice of the German courts shows that the negotiation framework as devised by the CJEU works well in practice. ${ }^{38}$ While a patentee is not able to obtain an injunction unless it offers a SEP license on FRAND terms, the implementer is not able to delay negotiations because it risks its behaviour being found in breach of the obligation to negotiate in good faith.

\footnotetext{
${ }^{33}$ Contreras et al. (2019): 160-201.

34 Risse (2018): 63.

${ }^{35}$ Risse (2018): 74-79; Contreras et al. (2019): 177-183.

36 C-170/13 Huawei Technologies v. ZTE, ECLI:EU:C:2015:477: para. 21-27.

37 C-170/13 Huawei Technologies v. ZTE: para. 60-68.

38 Risse (2018): 74-79; Contreras et al. (2019): 177-183.
} 


\section{REFUSAL TO LICENSE SEPs AT COMPONENT LEVEL}

Recently, the most controversial disputes related to access to standard essential patents concern licensing SEPs at component or end product level. Courts and competition authorities in multiple jurisdictions around the world have faced this issue in recent years. ${ }^{39}$ Some SEP holders decided to license manufacturers of end products only, rather than the manufacturers of components who implement inventions protected by SEPs. In such cases, establishing exclusionary behaviour is not always as obvious as it may seem at first sight. If the patentee licenses at the end product manufacturer level, while at the same time consistently refrains from seeking injunctive relief against component level manufacturers, then it is possible that such refusal will not harm competition. ${ }^{40}$ In particular, refusal in these circumstances does not necessarily have to exclude standard implementers from the market. ${ }^{41}$ Thus, though theoretically it is possible that refusals to license at component level will not result in the exclusion of competitors, in practice however such refusals have often been coupled with other anti-competitive practices which altogether led to market foreclosure.

The problem is best illustrated by the facts of a now widely discussed US antitrust case, namely Federal Trade Commission v. Qualcomm, as well as antitrust proceedings in other jurisdictions in the EU and Asia. ${ }^{42}$ Qualcomm is a manufacturer of chips that comply with $3 \mathrm{G}$ and $4 \mathrm{G}$ telecommunication standards and enable communication with cellular communication networks. Qualcomm holds strong market power on the chip market and manufacturers of end products, such as smartphones, are dependent on Qualcomm's chips. Without Qualcomm's chip supplies, producers of final products would not be able to supply markets with their products because other chip manufacturers were not able to supply the required chips in sufficient quantities.

Qualcomm also owns patents essential to the practice of $3 \mathrm{G}$ and $4 \mathrm{G}$ telecommunications standards. In addition, Qualcomm owns a large portfolio of non-SEPs as well as other SEPs concerning other standards. Like other participants in the standard-setting process, it pledged to license its patents to every willing licensee on FRAND terms. Qualcomm initially licensed its SEPs portfolio to all willing licensees, irrespective of the level of the supply chain at which they operated. Later, however, Qualcomm decided not to license rival chip manufacturers. Instead, it began to license manufacturers of end products, and it also raised the level of running royalties: from $3 \%$ calculated against the price of chips, to $5 \%$ calculated against the price of the final product incorporating Qualcomm's patented technology.

Qualcomm not only refused to license competing chip manufacturers. It also adopted a 'no license, no chips policy', making the supply of chips to

\footnotetext{
39 See above, the cases referred to in Section III.

40 Padilla, Wong-Ervin (2016): 18-20.

41 Padilla, Wong-Ervin (2016): 18-20.

42 See cases referred to in footnotes 15-18.
} 
producers of end products dependent on the conclusion of a SEP licensing agreement. Qualcomm offered discounts and rebates to its customers, making them conditional on the purchase of its own chips. It also concluded exclusive dealing arrangements concerning the supply of chips with one of its most important customers. Qualcomm's other licensing terms also raised significant concerns. Firstly, it initially licensed a patent portfolio comprised of SEPs and non-SEPs. Secondly, Qualcomm forced some of its licensees to cross-license their patents on a royalty-free basis and additionally also demanded that such licensees agree not to assert their patents against Qualcomm's other licensees. Thirdly, in some agreements Qualcomm required royalty payments after the expiry of the licensed patents.

Qualcomm refused to conclude SEP licenses with other chip manufacturers, its actual or potential competitors, and instead licensed only at the end product level. Qualcomm admitted that royalties were set as a percentage of the value of the end product. Thus, Qualcomm earned more by licensing at the end product level. Additionally, Qualcomm had a rebates scheme for those who bought its chips. It also entered into exclusive supply arrangements with those end product manufacturers. In practice, these additional arrangements resulted in the chips of other manufacturers' being more expensive for the end manufacturers than those of Qualcomm.

Qualcomm's conduct was clearly exclusionary. It resulted in serious competitive harm. There was sufficient evidence that as a result of Qualcomm's licensing policy Qualcomm's competitors had decided to exit the market. There was also ample proof that Qualcomm effectively raised its competitors' costs, making their chips more expensive. Qualcomm's customers had no incentives to purchase third-party chips as they obtained discounts and rebates only when they bought chips from Qualcomm. When manufacturers of end products bought chips from Qualcomm's competitors, they would still have to pay royalties but would not be entitled to rebates or discounts. What is more, as a result of refusing to license its competitors, Qualcomm was allowed to raise its royalties. By calculating the royalties on the price of the handset rather than the component, Qualcomm was able to extract much higher royalties, which the Court in FTC $v$. Qualcomm viewed as 'unreasonably high'. ${ }^{43}$

Recently, there have been similar disputes over component level licensing in the automotive industry, as the SEP holders - owners of patents reading on telecommunications standards - preferred to license at the car manufacturers' level rather than at the component manufacturers' level. ${ }^{44}$ Car manufacturers produce their products using multiple components com-

${ }^{43}$ FTC v. Qualcomm: 84.

${ }_{44}$ See the discussion concerning licensing in the automotive industry in: Brief of amicus curiae Continental Automotive Systems, Inc. and Denso Corporation in support of Appellee Federal Trade Commission (in case FTC v. Qualcomm), 29 November 2019 (CAS Brief); Brief of Association of Global Automakers and Alliance of Automobile Manufacturers as Amici Curiae Supporting Appellee (in case FTC v. Qualcomm), 29 November 2019 (AGA Brief) as well as by Florian Muller at <http://www.fosspatents.com>. 
ing from numerous suppliers. In order to ensure that their products can properly communicate, car manufacturers equip their cars with telematic control units. The producers of these telematic control units - referred to in the automotive industry as Tier One suppliers - buy modules for their products from Tier Two suppliers, who in turn buy the chips from Tier Three suppliers, namely chip manufacturers (including Qualcomm). It is in fact only the Tier Three manufacturers who implement inventions protected by SEPs into chips. SEP holders also refused to license all component suppliers even though at the standard-setting stage they voluntarily pledged to license their SEPs on FRAND terms to all willing licensees. Instead, these SEP holders preferred to license at the end product level. Again, the licensing scheme was supposed to conceal the desire by patentees to obtain the highest possible royalties, and again the royalties were calculated as a percentage of the product price. Disputes over refusals to license component makers are now pending before German courts.

Refusals to license component makers are strongly criticized. Firstly, final product manufacturers want to obtain fully licensed components from their makers. ${ }^{45}$ When licensing occurs at the component level, then together with the sale of the SEP implementing component, patents are exhausted and products incorporating patented inventions may freely circulate on the market. ${ }^{46}$ Quite understandably, manufacturers of highly complex final products do not want to get involved in negotiations over the licensing of technologies implemented in components. They may be discouraged from buying unlicensed products and risking patent infringement disputes. That in turn may influence component makers' willingness to invest in making such components and to engage in component design and development. ${ }^{47}$ Consequently, some may be discouraged from entering a component market, while others may be forced to exit. ${ }^{48}$

Secondly, it is the component manufacturer who is in a better position to assess the essentiality and validity of a particular standard essential patent. ${ }^{49}$ Additionally, the actual implementer is in a better position to assess the value of the contribution made by a given invention. ${ }^{50}$ In fact, the informational asymmetry becomes only greater as we move from the component level to the end product supply level in such a complicated sector as the automotive sector. ${ }^{51}$ What is more, the component manufacturer has a greater incentive to fight for the proper level of the licensing fee, because the royalty is much greater in proportion to the price of the component than to the overall cost of the end product. ${ }^{52}$ By denying licenses to component manufacturers, SEP

\footnotetext{
${ }^{45}$ CAS Brief: 8.

${ }^{46}$ AGA Brief: 6.

47 CAS Brief: 9.

48 CAS Brief: 10-12.

49 CAS Brief: 19; AGA Brief: 13.

50 CAS Brief: 19; AGA Brief: 13.

51 CAS Brief: 18; AGA Brief: 15-18.

52 CAS Brief: 21.
} 
holders might be able to charge more at end product level which may in turn lead to higher prices of end products for consumers..$^{53}$

Thirdly, patentees who set the rates based on the total value of the final product benefit from the value of all innovation embodied in the whole product rather than in a much smaller component ${ }^{54}$. This in fact introduces a form of a tax for the benefit of the SEP owners and results in the overcompensation of the SEP holders. ${ }^{55}$ This is problematic. Allowing SEP owners to benefit from a value that is attributable to third party inventions rather than their own SEPs leads to such overcompensation. A properly balanced patent system should not allow for such excessive compensation. After all, what constitutes an additional and unjustified reward for one set of patentees is at the same time an unjustified cost for the technology users on a given market.

In most of the cases, refusals to license at the component level will breach the FRAND commitment made by the SEP holders to the standard setting organization at the standard setting stage.${ }^{56} \mathrm{~A}$ patent injunction against an implementer operating at the component level, when such an implementer is willing to conclude a license, is also unlikely in many jurisdictions. The problem is whether such a breach necessarily implies a breach of competition law. That does not necessarily have to be the case. If there is no harm to competition, no breach of competition rules can be assumed. It is widely accepted that antitrust law - whether it is Article 2 Sherman Act in the US or Article 102 TFUE in the EU - requires that harm to competition be established.

There may be no harm to competition when the SEP holder licenses manufacturers of final products rather than manufacturers of components. As has already been observed above, this will be the case when the SEP holder does not, neither directly nor indirectly, discriminate against final product manufacturers on the basis of the components' source, and when the patentee does not assert their patents against any of the component manufacturers. ${ }^{57}$ Transparency with respect to the licensing scheme adopted would be very helpful in assessing the likelihood of such harm. This can be achieved if the SEP licensor publishes its licensing terms. Harm to competition is more likely when the SEP holder is a vertically integrated company, that is, if it operates both on the product and technology markets and competes with other component manufacturers. It is clear that a non-vertically integrated SEP holder will have no incentives to foreclose any of the competitors operating on the product market where the SEP protected inventions are implemented. In such circumstances the fact that a refusal could at the same time constitute a breach of obligations towards the standard setting organization, and result from a FRAND commitment made during a standard-setting process, cannot not influence the antitrust assessment of such conduct.

53 CAS Brief: 23.

${ }^{54}$ CAS Brief: 17-18; AGA Brief: 21.

55 CAS Brief: 22; AGA Brief: 9.

${ }^{56}$ Contreras, Layne-Farrar (2018a): 200-202. There the authors discuss the issue referring to US cases interpreting IPR policies of standard developing organizations.

57 Padilla, Wong-Ervin (2016): 18-20. 
In the disputes with Qualcomm, the competition authorities in numerous jurisdictions dealt with a SEP holder who was also present on the product market (chip market). Qualcomm was a vertically integrated company and apart from being present on the technology market, it also had a very strong position on the downstream chip market. The manufacturers of mobile devices were dependent on the supply of Qualcomm's chips. Chip sales on that downstream market were a source of substantial income for the company. Not surprisingly, Qualcomm had an incentive to adopt a licensing policy that would strengthen its position on the product market. It adopted a licensing model whereby it refused to license other component manufacturers and instead licensed manufacturers of final products. Qualcomm offered discounts and rebates to those manufacturers who used Qualcomm chips. This led to higher royalties for those manufacturers who used chips from sources other than Qualcomm's. Thus, the manufacturers of final products had absolutely no incentive to source chips from Qualcomm's competitors. During the period when Qualcomm adopted its licensing policy, coupled with exclusive dealing arrangements and rebates or discounts, most competitors exited the chip market.

Qualcomm's anticompetitive conduct was a combination of refusal to license its SEPs at the component level with certain other competition restricting clauses, such as exclusive dealing and rebate payment schemes that constituted an incentive to buy Qualcomm chips. The exclusionary nature of Qualcomm's practice was thus evident. Interestingly, Qualcomm's practice was also clearly exploitative. By moving from the level of component manufacturers to that of the final product manufacturers, Qualcomm sought to broaden its base for calculating running royalties. This consequently led to higher prices for customers of end products, as the higher royalty was most likely included in the final price. The ubiquitous use of Qualcomm's chips implies that quite a substantial number of customers must have been worse off as a result of Qualcomm's practices.

\section{CONCLUDING REMARKS}

Access to technologies protected by SEPs has triggered numerous patent wars. Interestingly, these wars were primarily wars between smartphone manufacturers concerning telecommunication standards such as $3 \mathrm{G}$ and $4 \mathrm{G}$. But with the emergence of $5 \mathrm{G}$ and the IoT, these wars are likely to be fought on markets for numerous other products that will implement standard communication technologies.

This paper shows that the refusal to license at the component level does not have to harm competition. This would be the case if the SEP holder does not discriminate against manufacturers of end products in terms of the source of the components they use. The fact that a licensor is not present on the market for components is a strong indicator that they would have no interest in harming competition at the component level. 
However, a vertically integrated SEP holder will have much stronger incentives to harm competition on the product market. By refusing to license other component manufacturers it may make their products much less attractive for end product manufacturers. This will especially be the case if end product manufacturers can obtain more favourable licensing terms, such as additional rebates, if they source their components from a vertically integrated SEP holder rather than its competitors. The decisions by competition authorities and courts in the EU, Asia and the US show that some vertically integrated SEP holders are less likely to resist the temptation to harm competition on the markets for components.

Rafat Sikorski

Adam Mickiewicz University, Poznań

rms@amu.edu.pl

https://orcid.org/0000-0002-1877-6777

Biddle, C.B. (2018). No standards for standards: understanding the ICT standards-development ecosystem, [in:] J. Contreras (ed.), The Cambridge Handbook of Technical Standardization Law. Cambridge: $17-28$.

Contreras, J. (2018). Introduction, [in:] J. Contreras (ed.), The Cambridge Handbook of Technical Standardization Law. Cambridge: $1-4$.

Contreras, J., Layne-Farrar, A. (2018a). Non-discrimination and FRAND commitments, [in:] J. Contreras (ed.), The Cambridge Handbook of Technical Standardization Law. Cambridge: 186-208.

Contreras, J., Cotter, T.F., Jong, S.J., Love, B.J., Petit, N., Picht, P., Siebrasse, N.V., Sikorski, R., Suzuki, M., de Werra, J. (2019). The Effect of FRAND Commitments on Patent Remedies [in:] C.B. Biddle, J.L. Contreras, B.J. Love, N.V. Siebrasse (eds.), Patent Remedies for Complex Products. Cambridge: 160-201.

Delrahim, M. (2018). The "New Madison" approach to antitrust and intellectual property law, Philadelphia, 16 March 2018. <https://www.justice.gov/opa/speech/file/1044316/download>.

Delrahim, M. (2017). Take it to the limit: respecting innovation incentives in the application of antitrust law, Los Angeles, 10 November 2017. <https://www.justice.gov/opa/speech/file/ 1010746/download>.

Gupta, K. (2018). How SSOs work: unpacking the mobile industry's 3GPP standards, [in:] J. Contreras (ed.), The Cambridge Handbook of Technical Standardization Law. Cambridge: 29-44.

Gupta, K. (2019). 5G and its anticipated intellectual property and antitrust policy issues. CPI Antitrust Chronicle, September 2019: 29-34.

Hovenkamp, H.J. (2019). FRAND and Antitrust Faculty Scholarship at Penn Law. <https://scholarship.law.upenn.edu/faculty_scholarship/2093>.

Lemley, M.A., Shapiro, C. (2007). Patent hold-up and royalty stacking. Texas Law Review 85: 1991-2049.

Padilla, J., Wong-Ervin, K.W. (2016). Portfolio Licensing at the End-User Device Level: Analyzing Refusals to License FRAND-Assured Standard-Essential Patents at the Component Level. $<$ https://ssrn.com/abstract=2806688>.

Pohlmann, T., Blind, K. (2016). Landscaping Study on Standard Essential Patents (SEPs), Study commissioned by DG Grow, European Union.

Regibeau, P., de Cornick, R., Zenger, H. (2016). Transparency, Predictability, and Efficiency of SSO-based Standardization and SEP Licensing. A Report for the European Commission. European Union.

Risse, A. (2018). Injunctions in Germany, [in:] R. Sikorski (ed.), Patent Law Injunctions. Alphen Aan den Rijn: 63-86. 
Sikorski, R. (2018). Between automatism and flexibility: injunctions in 21st century patent law, [in:] R. Sikorski (ed.), Patent Law Injunctions. Alphen Aan den Rijn: 239-250.

Teece, D.J. (2019). 5G and the global economy: how static competition policy framework can defeat open innovation. CPI Antitrust Chronicle, September 2019: 13-20.

Siebrasse, N.V., Sikorski, R., Contreras, J.L., Cotter, T.F., Golden, J., Jong, S.J., Love, B.J., Taylor, D.O. (2019). Injunctive relief, [in:] C.B. Biddle, J.L. Contreras, B.J. Love, N.V. Siebrasse (eds.), Patent Remedies for Complex Products. Cambridge: 115-159.

\section{ACCESS TO STANDARD ESSENTIAL PATENTS AND ANTITRUST ENFORCEMENT: THE CASE FOR LICENSING COMPONENT MANUFACTURERS}

\section{Summary}

The ability to compete on numerous markets today depends on access to technological standards. When standards are protected by standard essential patents (SEP), a license to use such SEPs will be required. There have been numerous disputes in various jurisdictions over refusals to license SEPs. Most recently, disputes concern access to SEPs by the manufacturers of components. Some SEP holders deny access to their standard essential patents to component manufacturers and prefer to license end product producers. This practice has become a highly contentious issue around the world. In particular, manufacturers of components who are denied access to SEPs claim that such refusals amount to violations of competition rules. The author examines this highly contested practice is an attempt to show when denying access to an SEP license could harm competition.

Keywords: standard essential patents (SEPs); FRAND licenses; refusal to license; licensing at component level; technical standards 
